\title{
HIV/HCV Co-Infection—A Dual Neurocognitive Problem
}

\author{
Kalwa Agnieszka $^{1 *}$, Szymanska Bogna ${ }^{2}$, Cholewinska Grazyna ${ }^{3}$, Siwy-Hudowska Anna ${ }^{2}$ \\ ${ }^{1}$ Institute of Psychiatry and Neurology, Addiction Prevention and Treatment Unit, Warsaw, Poland; ${ }^{2}$ Warsaw School of Social Sci- \\ ences and Humanities, Warsaw, Poland; ${ }^{3}$ Warsaw Hospital for Infectious Diseases, Warsaw, Poland. \\ Email: ${ }^{*} k a l w a @ i$ ipin.edu.pl
}

Received December $2^{\text {nd }}, 2011$; revised January $10^{\text {th }}, 2012$; accepted February $5^{\text {th }}, 2012$

\begin{abstract}
Presence of the hepatitis $\mathrm{C}$ virus in HIV infected patients has an additional neurotoxic influence on the Central Nervous System. It has been described that HCV co-infection leads to neuropsychological impairment whose severity is greater than in mono-HIV infected subjects. In the present study we assessed the neuropsychological status of 46 human immunodeficiency virus (HIV)-infected individuals from the Warsaw Hospital for Infectious Diseases. For the purpose of cognitive assessment, neuropsychological tests measuring global cognitive functions, attention and perception, verbal memory, as well as non-verbal aspects of executive functions, e.g. visual monitoring and planning, were assessed. In $60 \%$ of the investigated patients, who were co-infected with the hepatitis $\mathrm{C}$ virus, the overall cognitive outcome observed was worse than in mono-HIV infected subjects. The following factors were taken into account: ART therapy's influence on cognitive functions using the CPE rank (CNS Penetration Efficacy, 2010), route of HIV transmission, conditions of human existence and age of investigated patients. The present work should be treated as a preliminary research and interpreted in the context of several limitations described in the text.
\end{abstract}

Keywords: HIV; HCV; Cognitive Functions; Co-Infection

\section{Background}

In the era of antiretroviral treatment (ART), it is not protection from death but from life with serious neurocognitive disorders that poses a challenge in the treatment of patients with a human immunodeficiency virus (HIV) infection. Brain function abnormalities are observed in approximately $20 \%-40 \%$ of HIV-infected individuals. As a result, neurocognitive disorders are present in various domains: attention, processing speed, psychomotor functions, learning, memory, working memory and executive functions. Executive functions are higher order cognitive processes that encompass skills necessary for purposeful, goal-directed behavior and are essential for the ability to respond to novel and unfamiliar situations [1]. Impaired cognition causes behavioral and emotional consequences. Previous studies have noted that HIVinfected patients demonstrate significant impairments in facial emotion recognition, specifically for fear [2]. Cognitive deficits cause problems in everyday life that result in impairment in the ability to assess new information, as well as planning and monitoring behavior. This has a great impact on the patient's quality of life. According to Lindl et al., a significant number of HIV-infected individuals may develop, at present or in the future, severe

\footnotetext{
*Corresponding author.
}

cognitive dysfunctions [3]. HIV-associated neurocognitive disorders classified presently as the HAND syndrome may occur with different intensity [4]. The criteria of HAND, as defined by the American Academy of Neurology in 1991, were revised in 2007 [5]. At present, they are divided into three categories: 1) asymptomatic neurocognitive impairment (ANI), i.e. a mild cognitive dysfunction detected in neuropsychological tests; 2) mild neurocognitive disorders (MND); 3) HIV-associated dementia (HAD) that may be observed even in young individuals, a serious neurocognitive disorder that leads to significant difficulties in everyday functioning. The severity of impairment is not only a consequence of infection, but also depends on age and specificity of antiretroviral treatment. Although drug penetration to the central nervous system (CNS) is not as efficient as to plasma, combination antiretroviral therapy (cART) with 3 agents improves the general cognitive outcome. Particular agents, however, differ in ability of penetration to cerebrospinal fluid (CSF). This can result not only in limiting the potential chance of cognitive improvement but also in the worsening of cognitive functions [6]. Some authors indicated that neurocognitive functions and metabolic brain changes in proton magnetic resonance spectroscopy differ in patients treated with a different regimen of cART [7]. Moreover, cognitive functioning tends to be 
more impaired in patients with poor medication adherence [8].

The HIV-positive population is quite specific, as the patients often come from high-risk environments (e.g. illicit drug users) exposing them to different types of blood-borne infections. There is a significant number of patients with the hepatitis $\mathrm{C}$ virus among the HIV-infected individuals. Prevalence of the HCV virus in HIVinfected patients is greater than that of the HBV virus [9]. About $40 \%$ of HIV-positive patients are co-infected with $\mathrm{HCV}$, while the number is as high as $80 \%$ among drug abusers [10]. There is strong evidence that co-infected patients develop more severe neurocognitive disorders compared to mono-infected subjects. The presence of $\mathrm{HCV}$ in the Central Nervous System (CNS) enhances expression of HIV in the brain tissue and ART is not sufficient to halt the complications caused by $\mathrm{HCV}$ $[11,12]$.

It is likely that HIV and HCV-related impairment is underlined by similar mechanisms. Both types of infections cause disruption of the circuits connecting subcortical structures with prefrontal and frontal white matter [13]. This results in dysfunctions of cognitive processes associated with cortical and subcortical structures. Similar structural abnormalities are observed in mono-HCV infected patients, in whom the same areas of cognitive dysfunctions as in HIV-infected subjects are present. Magnetic resonance spectroscopy showed metabolic abnormalities in these areas [14]. Cognitive dysfunctions in mono HCV-infected patients are found by a majority of authors describing this particular problem. According to some of them, these abnormalities have the severity of mild cognitive impairment, and might be not as intense as in some HIV-positive individuals at the HIV-dementia stage [15]. Nevertheless, they exert influence on the patient's quality of life by degrading it [16]. Problems with motor coordination and information processing speed, as described in the literature, impact the patient's everyday functioning [17]. Although many studies proved that cognitive dysfunctions are associated with HIV or HCV infections, so far only a few of them described the neurocognitive problems in patients with the $\mathrm{HIV} / \mathrm{HCV}$ co-infection. In all of these studies, dually infected patients achieved results that were worse than those of mono-infected subjects.

Not only those authors who aimed to investigate the difference between mono and co-infected patients identified significantly worse results in subjects co-infected with HCV. Fama et al. [18] measured semantic memory in chronic alcoholics with and without HIV co-infection and in non-alcoholic, HIV-infected subjects. Remote semantic memory tests rendered worse results in all three investigated groups of individuals who were co-infected with HCV.

\section{Objectives of the Study}

In our present study, and in the continuing analysis of other authors' research, we confirmed the hypothesis claiming that neurocognitive disorders are more severe in $\mathrm{HIV} / \mathrm{HCV}$ co-infected individuals than in mono-infected individuals to be true. This study, however should be treated as a preliminary research, and interpreted in the context of limitations described below (in the discussion part). Our aim was to assess the cognitive status of 46 subjects (38 males, 8 females), who were undergoing antiretroviral treatment (ART), and to find statistically significant in-group differences taking into account the patients' current medical status, HCV co-infection, ART therapy's influence on cognitive functions using the CPE rank (CNS Penetration Efficacy, 2010), routes of HIV transmission, conditions of human existence, as well as selected demographic and psychosocial data. We were particularly interested in finding differences between population with mono HIV infection and $\mathrm{HIV} / \mathrm{HCV}$ co-infection.

\section{Material and Methods}

The present research was conducted in the Warsaw Hospital for Infectious Diseases, within the database of the HIV outpatient clinic, which contains currently about 3000 HIV-positive patients. $46 \mathrm{HIV}$-infected adult individuals ( 38 males, 8 females) were recruited by voluntary participation in neuropsychological testing. Inclusion criteria were HIV or HIV/HCV positive status. Patients with history of not HIV-related neurological disorders e.g. severe neurological trauma, as well as subjects with clinical diagnoses of hepatic encephalopathy, were excluded from the study. The participants were selected according to mono HIV infection and HIV plus HCV infection status. Hepatitis $\mathrm{C}$ infection was confirmed by presence of anti-HCV antibodies and Real Time method PCR HCV-RNA. In this sample, patients were treated neither with interferon nor ribavirin and had no previous history of such treatment. All participants were treated with antiretroviral drugs within various regimens. The influence of antiretroviral therapy on cognitive function was calculated using CPE rank (CNS Penetration Efficacy, 2010).

All the neuropsychological methods used in the present research were based on Polish language tests meeting the criteria of adaptation and population norms. All patients taking part in the research gave their written informed consent. Data concerning demographic, clinical and psychosocial factors, e.g. age, sex, duration of HIV infection, coexisting HCV infection, education level, HIV transmission, employment and social support, were collected in an individual questionnaire. The neuropsychological investigation was performed by a psycholo- 
gist.

For neuropsychological assessment, the following tests were used:

Mini-Mental State Examination MMSE which is commonly used in cognitive functioning screening tests measuring global cognitive functions, such as attention and orientation, memory, visuospatial and language abilities.

TUS-the Ciechanowicz Attention and Perceptiveness Tests (TUS) assessing visual attention span. In this task the subject is asked to cross out certain digits within a limited time period. There are 4 test versions available with numbers, letters or non-verbal digits. In the present investigation the $3 / 8$ version was used, and processing speed, as well as the number of ignored digits were taken into account.

WAIS-R forward and backward digit repetition test to measure verbal memory and some aspects of working memory in a backward repetition task.

RFFT Ruff Figural Fluency Test was used for the measurement of non-verbal aspects of executive functions, such as planning and monitoring skills. The subject is asked to create as many new visual designs as possible within a limited time period. The number of unique designs was estimated.

The statistical analysis was performed with the statistical package SPSS Version18.0. Due to small sample size and its multifactorial character, non-parametric tests were used. For quantitative traits the mean values and standard deviations were calculated. T-Tests for independent groups and U-Mann Whitney non-parametric tests for two groups were counted to verify statistically significant differences between the group of mono HIVinfected and the group of HIV/HCV co-infected patients.

\section{Results}

\subsection{Basic Descriptive Statistics}

The descriptive statistics for mono HIV-infected and HIV/HCV co-infected patients' groups are shown in Table 1. It is worth indicating, however, that some information (mainly psychosocial data) was simply reported by the investigated patients, and its' credibility was not verifiable.

The age of patients in the overall group of 46 subjects ranged from 21 to $58(\mathrm{M}=37.02 ; \mathrm{SD}=8.81)$. As mentioned above, the number of patients with the HIV/HCV co-infection was $28(60 \%)$. In the mono HIV-infected group there were 18 individuals aged 21 - $58(\mathrm{M}=33.3$; $\mathrm{SD}=10.6)$. The age difference between both groups was statistically significant: $t(44)=2.39 ; p=0.02$; patients with the $\mathrm{HIV} / \mathrm{HCV}$ co-infection (28 individuals) were older $(\mathrm{M}=39.4 ; \mathrm{SD}=6.6)$.

The mean duration of HIV infection (number of years from diagnosis) in the mono HIV-infected group was 5 years $(\mathrm{SD}=5.5 ; 0-17$ years; where 0 is defined as a few months). In the group with the HIV/HCV co-infection, the mean was significantly higher: $\mathrm{M}=15.1 ; \mathrm{SD}=5.6$ : $\mathrm{t}$ $(44)=6.20 ; p<0.01$.

There were no significant differences between the groups in terms of the mean years of education $(\mathrm{t}(44)=$ $0.91 ; \mathrm{p}=0.37)$. The mean for the mono HIV-infected group was $12.3(\mathrm{SD}=2.6)$, while for the $\mathrm{HIV} / \mathrm{HCV}$ co-infected group was 11, $6(\mathrm{SD}=2.6)$.

Although $72 \%(\mathrm{~N}=13)$ of mono HIV-infected patients were currently employed, only $27 \%(\mathrm{~N}=8) \mathrm{pa}$ tients from the comparative co-infected group had a job. The opposite proportion was observed in the range of convictions: only $17 \%(\mathrm{~N}=3)$ of mono HIV-infected patients, and as many as $71 \%(\mathrm{~N}=20)$ of $\mathrm{HIV} / \mathrm{HCV}$ coinfected subjects were convicted with a court sentence.

The majority of patients (24) with the HCV co-infection had a history of illicit-drug use, and 9 of them suffered from alcohol dependence. In the group of mono HIV-infected patients there were only 3 illicit drug users and 5 individuals with alcohol abuse.

In the group of mono HIV-infected subjects, 14 individuals got infected in the situation of MSM (male sex male) risky behaviors. Only 3 of them were infected through heterosexual contact (Hxs), and one patient

Table 1. Basic characteristics of mono HIV-infected and HIV/HCV co-infected patients. Selected medical, anamnestic and demographic data.

\begin{tabular}{|c|c|c|}
\hline Variable & $\begin{array}{l}\text { HIV infection } \\
\mathrm{N}=18\end{array}$ & $\begin{array}{c}\mathrm{HIV} / \mathrm{HCV} \\
\text { co-infection } \mathrm{N}=28\end{array}$ \\
\hline Age & $\begin{array}{c}\mathrm{M}=33.3 \\
\mathrm{SD}=10.6(21-58)\end{array}$ & $\begin{array}{c}M=39.4 ; \\
S D=6.6(29-52)\end{array}$ \\
\hline Education (years) & $\begin{array}{c}\mathrm{M}=12.3 \\
\mathrm{SD}=2.6(8-17)\end{array}$ & $\begin{array}{c}M=11.6 \\
S D=2.6(6-17)\end{array}$ \\
\hline $\begin{array}{l}\text { Duration of disease (years } \\
\text { from the moment of HIV } \\
\text { diagnose) }\end{array}$ & $\begin{array}{c}\mathrm{M}=4.7 \\
\mathrm{SD}=5.5(0-17)\end{array}$ & $\begin{array}{c}\mathrm{M}=15.1 \\
\mathrm{SD}=5.6(3-22)\end{array}$ \\
\hline Currently employed & $\mathrm{N}=13$ & $\mathrm{~N}=8$ \\
\hline $\begin{array}{l}\text { Convicted with the court } \\
\text { sentence }\end{array}$ & $\mathrm{N}=3$ & $\mathrm{~N}=20$ \\
\hline \multicolumn{3}{|l|}{ Way of HIV transmission: } \\
\hline IDU & $\mathrm{N}=1$ & $\mathrm{~N}=20$ \\
\hline Hxs & $\mathrm{N}=3$ & $\mathrm{~N}=1$ \\
\hline MSM & $\mathrm{N}=14$ & $\mathrm{~N}=7$ \\
\hline AIDS & $\mathrm{N}=10$ & $\mathrm{~N}=5$ \\
\hline \multicolumn{3}{|l|}{ Current CD4: } \\
\hline$\leq 200$ & $\mathrm{~N}=16$ & $\mathrm{~N}=21$ \\
\hline$>200$ & $\mathrm{~N}=2$ & $\mathrm{~N}=7$ \\
\hline
\end{tabular}


through illicit drug use (IDU). In the majority of patients (20) from the HIV/HCV co-infected group, HIV was transmitted by illicit drug use (IDU). Only 7 patients got infected through MSM risky behaviors and one patient through heterosexual contact (Hxs). Moreover, 5 (18\%) subjects from this group were in an advanced stage of AIDS whereas in the group of mono HIV-infected patients, there were $10(56 \%)$ individuals with AIDS.

The CD4 count was equal to or lower than 200 cells $/ \mathrm{mL}$ in 16 subjects and higher than 200 cells $/ \mathrm{mL}$ in 2 mono HIV-infected patients. In the comparative group, the proportions were similar: in 21 subjects the CD4 level was equal to or lower than 200 and in 7 individuals higher than 200 cells $/ \mathrm{mL}$.

About $60 \%$ of individuals from the co infected group had a CPE rank equal to or higher than 7 (according to classification 2010), while the remaining patients (about 40\%) had a CPE ratio lower than 7 (Table 2).

\subsection{Neuropsychological Tests-Differences between Groups (U Mann-Whitney's Tests)}

Statistical analyses were performed in both groups with the use of non-parametric U Mann-Whitney's Tests. We decided not to use parametric analyses because of the different frequencies of participants in the groups compared, and additionally, due to differences in dependent variables.

The results indicated several significant differences (see Table 3) between mono and dually infected patients. As expected, HCV co-infection was significantly more frequent in cases of worse neuropsychological test performance.

In comparison with mono infected subjects, patients with $\mathrm{HIV} / \mathrm{HCV}$ co-infection needed more time to complete TUS attention and perceptiveness tests (Mrang1 $=$ 28.9, Mrang2 $=19.4$ respectively; $\mathrm{U}=339.0 ; \mathrm{p}=0.02$ ). The difference between groups was significant also in terms of standardized scores: Mrang1 $=28.2$; Mrang2 $=$ $19.9 ; \mathrm{U}=325.0 ; \mathrm{p}=0.03$. The comparisons are illustrated in Figure 1.

The HIV/HCV co-infected patients repeated number sequences in the WAIS-R digit repetition test less successfully (Mrang2 $=20.1$ ) compared to mono HIV-infected subjects (Mrang1 $=28.8$ ). That difference was also statistically significant: $\mathrm{U}=346.5 ; \mathrm{p}=0.03$ (see Figure 2).

The results also showed a weaker action strategy in creating unique designs in the Ruff Figure Fluency Test (RFFT) in dually infected patients (Mrang2 $=20.4$ ) compared to mono HIV-infected individuals (Mrang1 $=28.3$ ); $\mathrm{U}=338.5 ; \mathrm{p}=0.05$. The differences were statistically significant also according to standardized T-scores (Mrang1 $=28.7$, Mrang2 $=20.2 ; \mathrm{U}=345.5 ; \mathrm{p}=0.04$ ) and $\mathrm{C}$-scores (Mrang1 $=28.6$, Mrang2 $=20.2 ; \mathrm{U}=343.5$;

Table 2. CPE ratio in investigated group of HIV/HCV coinfected patients.

\begin{tabular}{ccc}
\hline CPE & CPE $<7$ & CPE $\geq 7$ \\
\hline $\mathrm{N}(\%)$ & $11(39.3 \%)$ & $17(60.7 \%)$ \\
\hline
\end{tabular}

Table 3. Differences in neuropsychological tests performance between patients mono HIV-infected and HIV/HCV co-infected: descriptive statistics and U Mann-Whitney's tests scores.

\begin{tabular}{|c|c|c|c|c|c|c|c|}
\hline Neuropsychological test & Mean $N=46$ & $\begin{array}{l}\text { Standard } \\
\text { deviation }\end{array}$ & $\begin{array}{l}\text { Mono HIV mean } \\
\text { range } \mathrm{N}=18\end{array}$ & $\begin{array}{l}\mathrm{HIV} / \mathrm{HCV} \text { mean } \\
\text { range } \mathrm{N}=28\end{array}$ & $\begin{array}{l}\text { U Mann Whitney } \\
\text { (score) }\end{array}$ & $\begin{array}{l}\text { Standard } \\
\text { error }\end{array}$ & p value \\
\hline MMSE & 27.61 & 2.43 & 23.03 & 23.80 & 243.5 & 43.66 & 0.846 \\
\hline MMSE (WT) & 47.02 & 13.33 & 21.97 & 24.48 & 224.5 & 44.33 & 0.535 \\
\hline TUS $3 / 8$ processing speed & 546.84 & 131.11 & 28.94 & 19.39 & 339.0 & 42.71 & 0.018 \\
\hline TUS $3 / 8$ number of ignored digits & 6.44 & 7.78 & 26.03 & 21.16 & 289.5 & 42.41 & 0.225 \\
\hline $\begin{array}{l}\text { TUS } 3 / 8 \text { number of ignored digits } \\
\text { (quartile) }\end{array}$ & 2.36 & 1.11 & 24.97 & 21.8 & 271.5 & 41.12 & 0.415 \\
\hline TUS $3 / 8$ number of errors & 0.20 & 0.41 & 23.79 & 22.52 & 251.5 & 29.60 & 0.648 \\
\hline WAIS digit repetition test & 9.50 & 3.60 & 28.75 & 20.12 & 346.5 & 44.16 & 0.032 \\
\hline RFFT number of unique designs & 67.46 & 23.35 & 28.31 & 20.41 & 338.5 & 44.41 & 0.051 \\
\hline $\begin{array}{l}\text { RFFT number of unique designs } \\
\text { (T score) }\end{array}$ & 47.28 & 9.53 & 28.69 & 20.16 & 345.5 & 44.36 & 0.035 \\
\hline $\begin{array}{l}\text { RFFT number of unique designs } \\
\text { (C score) }\end{array}$ & 41.52 & 28.13 & 28.58 & 20.23 & 343.5 & 44.41 & 0.039 \\
\hline RFFT error factor 2 & 4.44 & 1.04 & 21.83 & 23.78 & 222.0 & 33.53 & 0.531 \\
\hline
\end{tabular}




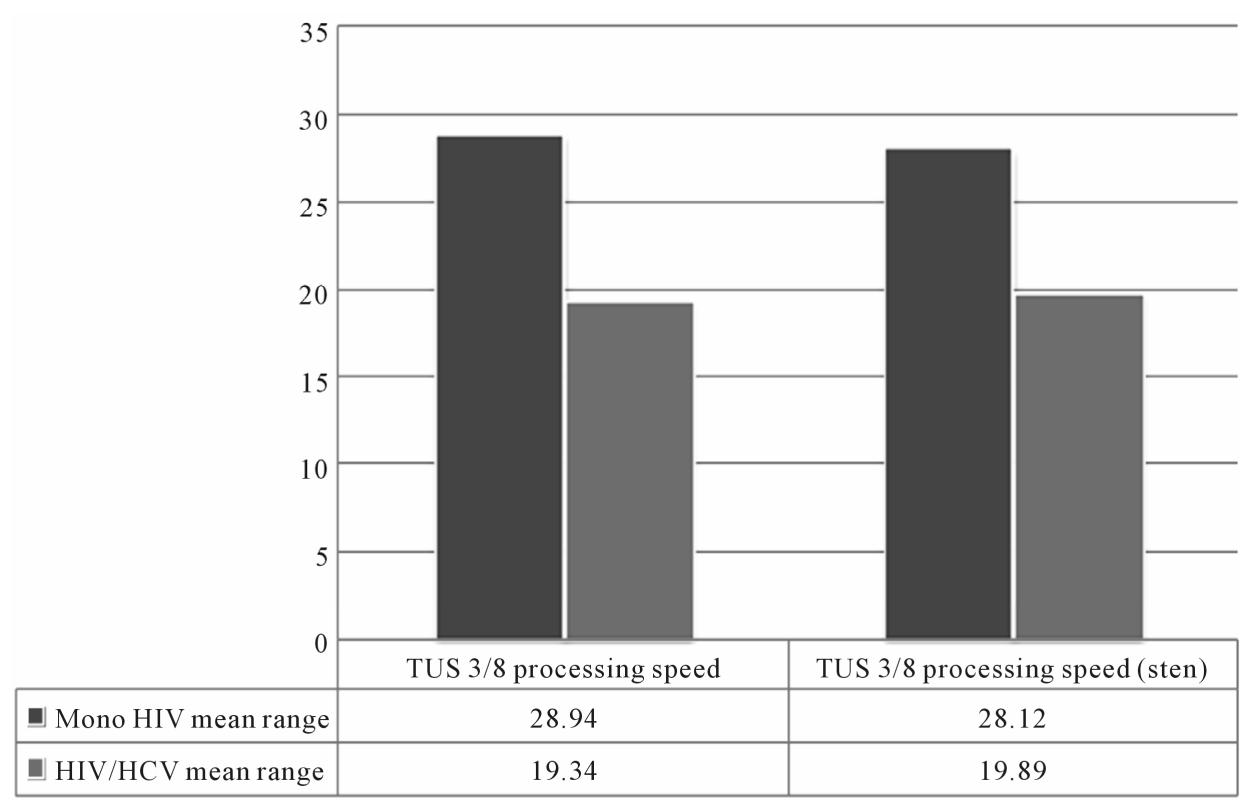

Figure 1. TUS 3/8 processing speed test: mean ranges between mono HIV-infected and HIV/HCV co-infected subjects.

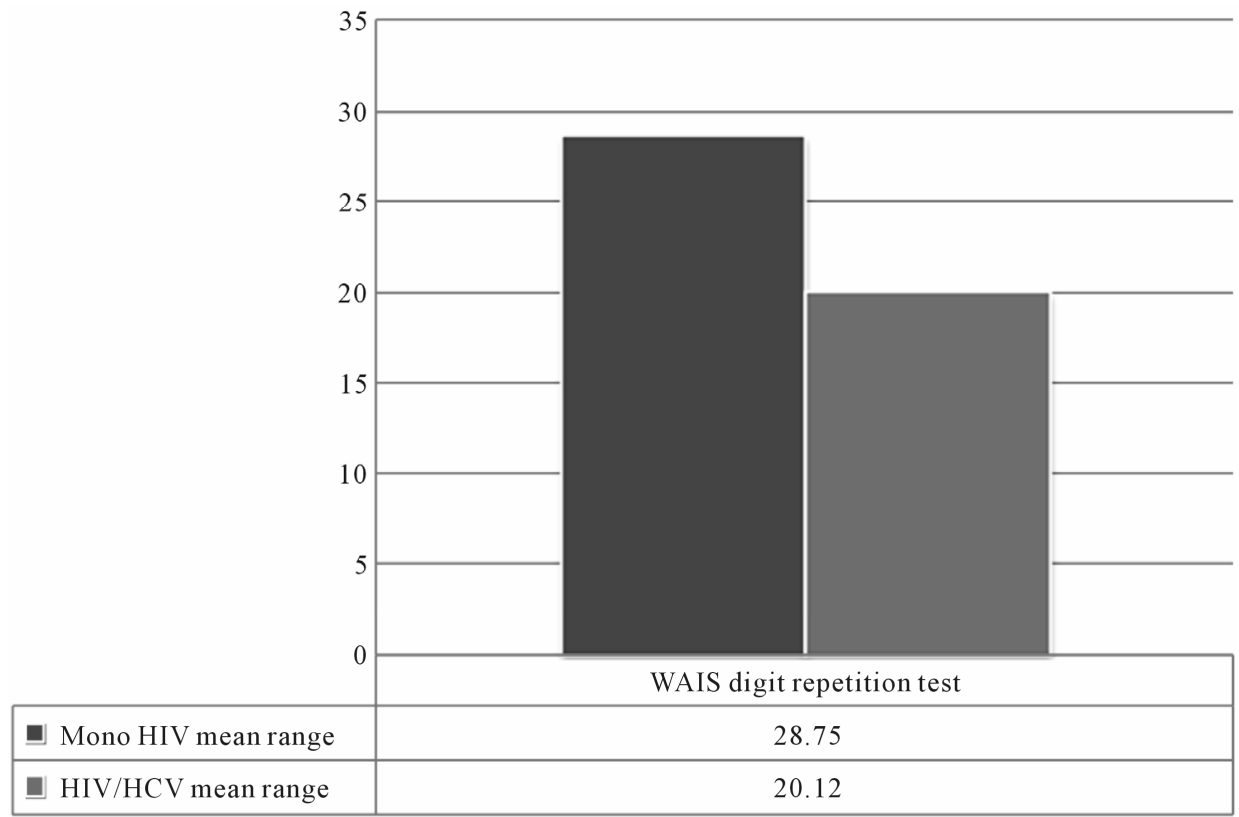

Figure 2. WAIS digit repetition test: mean ranges between mono HIV-infected and HIV/HCV co-infected subjects.

$\mathrm{p}=0.04)$. All comparisons are illustrated in Figure 3. Patients who were illicit drug users tended to render worse results in neuropsychological tests (TUS attention test and WAIS-R digit repetition test) compared to patients with HIV MSM transmission. No significant differences were associated with the CPE ratio $(<7 \mathrm{n}=16$ and $\geq 7 \mathrm{n}=26$ ), CD4 cell count and age of the patients.

\section{Discussion}

Results of this present study seem to confirm similar findings of other authors. In the assessed group, co-infected individuals achieved significantly worse results in neuropsychological tests measuring attention, perception and verbal learning processes, as well as non-verbal aspects of executive functions, including planning and behavior monitoring. In comparison with mono-infected patients, they had slower performance times in tests measuring both visual and verbal domains. That would be an argument for general impairment of mental processes and an overall slowing, in spite of the fact that there were no significant differences between both groups in 


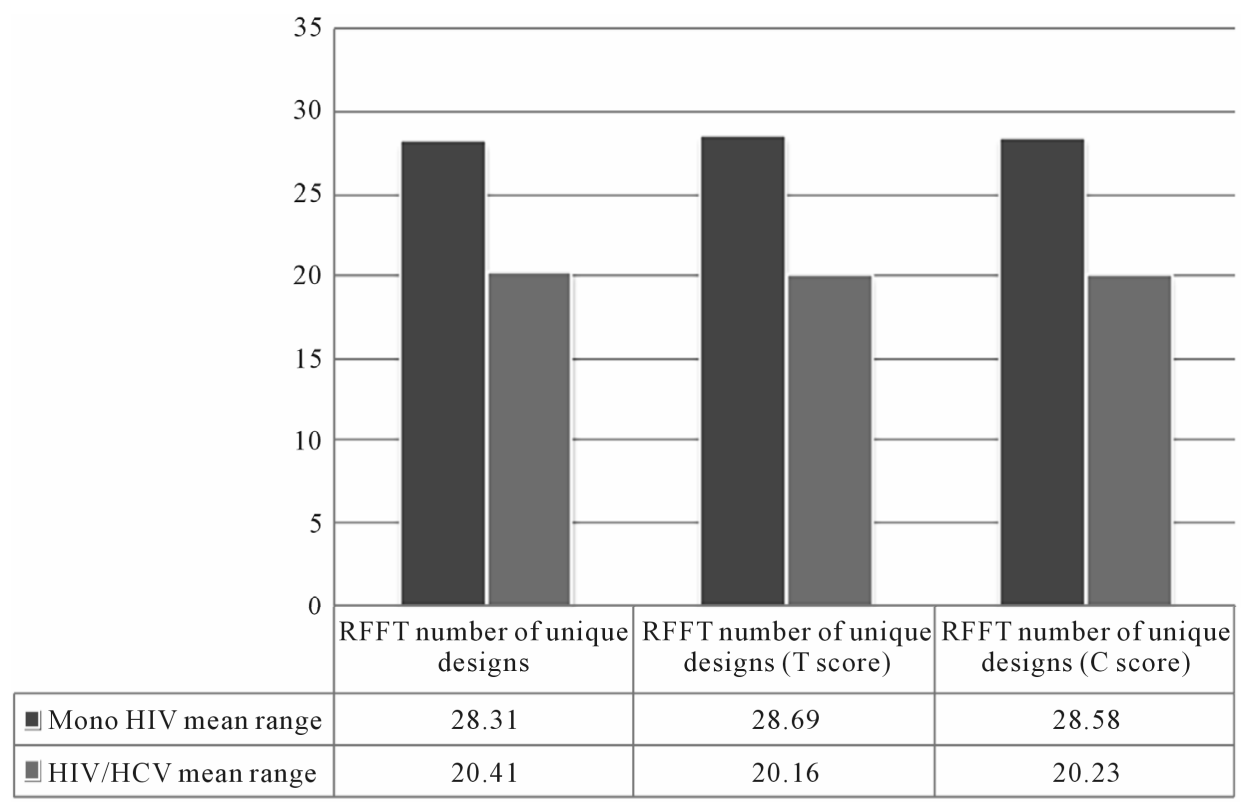

Figure 3. RFFT number of unique designs: mean ranges between mono HIV-infected and HIV/HCV co-infected subjects.

MMSE scale results. This method is a global cognitive function screening scale, but is commonly used in Alzheimer-type dementia and measures cognitive functions connected with "cortical" rather than "frontal-cortical" cognitive functions specific for HIV dementia [19]. On the other hand, the recommended HIV-de-mentia scale which is considered to be better for the global cognitive assessment of HIV-infected individuals, has not been normalized in Poland yet. The MMSE scale has, and it corresponded better with other selected tests used in this research.

There are several limitations to our present research. Additional factors beyond $\mathrm{HCV}$ co-infection could worse patients' overall cognitive outcome, however, its influence is not easy to assess. It is worth indicating the meaning of other differences in the characteristics of the two groups described (mono HIV-infected and HIV/HCV co-infected patients). The duration of illness (years lived with HIV diagnosed) was much longer in the dually-infected group and the fact that patients living longer with the virus exerting a devastating influence on the CNS produced worse cognitive outcome, is not surprising. However, the source of $\mathrm{HCV}$ contamination is difficult to prove, and we cannot exclude that the patients' overall cognitive and clinical outcome became worse from the moment of becoming infected with the hepatitis $C$ virus. Nevertheless, it can be assumed that $\mathrm{HIV} / \mathrm{HCV}$ co-infected patients were in an overall worse medical condition, taking into account that 25 of them were in advanced stages of AIDS, while in the group of mono HIV-infected patients only 10 met these criteria. Moreover, as other authors who had not included patients with clinical diagnoses of hepatic encephalopathy to the study, we cannot exclude that some of the individuals might have had it at slight or sub-clinical level [20].

On the other hand, neither the CPE rank nor the CD4 cell count turned out to be significant for the in-group differences in the neuropsychological test performance of the entire group $(n=46)$. This could suggest that the CNS penetration efficacy and age of subjects in the investigated group were less meaningful for cognitive function, compared to $\mathrm{HCV}$ co-infection.

The majority of HIV/HCV co-infected group were illicit drug users, while only 3 mono HIV-infected patients had a history of this type of drug use. This (IDU) was the most significant route of virus transmission in duallyinfected patients, while in mono HIV-infected subjects the majority got infected by MSM risky behaviors. It is likely that the history of illicit drug use had an impact on the patients' worse social functioning and therefore we cannot exclude its influence on other psychosocial differences between mono and dually infected individuals. Although both groups had a similar mean number of years of education, the majority of mono-HIV infected patients were employed, while only 8 dually-infected subjects had a job. Twenty of HIV/HCV co-infected subjects and only 3 of mono HIV-infected patients had been convicted with a court sentence. We can assume that illicit drug use could also had an impact on patients' cognitive functioning. In our sample, the majority of MSM patients got infected by sexual contact, however we cannot exclude their occasional past or current use of psychoactive substances (including illicit drugs), although the individuals did not report it in the present 
investigation. There are not many studies comparing the cognitive status of HIV/HCV co-infected illicit drug users and patients with different routes of virus transmission. In the research of Ryan et al. who investigated 116 HIV-positive individuals, among whom 67 were coinfected with $\mathrm{HCV}$, there were no statistically significant differences in neuropsychological test performance among patients with and without past dependence of opiates, cocaine, or stimulants [21]. Although the authors used a broad range of neuropsychological tests, illicit drug users performed worse only on visual memory test, compared to other investigated subjects.

Other limitations of the present work are associated with the small study sample that makes final results less meaningful, however obtained differences were statistically significant (the $\mathrm{p}$ value statistics ranged from 0.02 to 0.05 ). Nevertheless, our findings should be treated as a preliminary research, and interpreted with caution.

Although various authors indicate that in $\mathrm{HIV} / \mathrm{HCV}$ co-infected patients slowing of overall mental processes is observed, it is still quite difficult to explain, due to limited number of research projects in this field, the nature of cognitive impairment in these individuals. The research by Gonzalez et al., as mentioned above, indicated that although patients with the mono HIV infection performed worse on Stroop Word-Color Interference Task compared to healthy (non-HIV and non-HCV infected) controls, their results were better compared to HIV/HCV co-infected patients [13]. Moreover, results of mono-infected patients differed from the control group only under one task condition (condition of maximally stressed mental capacity-naming the word color), while dually infected individuals performed worse under all three task conditions (reading color words in black, reading color words, naming the word color). According to these results, coexistence of HCV may be connected with the overall slowing of mental processes. Hinkin et al. came to a similar conclusion [20]. The authors investigated 118 individuals, among whom 35 were also infected with $\mathrm{HCV}$, using a comprehensive test battery measuring abstraction and executive functions, information processing, attention, learning, memory, verbal fluency, motor functions and global cognitive function. Individuals with HIV/HCV co-infection not only showed overall global cognitive impairment but also performed worse in more specific learning and memory tasks. In the study of Ryan et al., mentioned above, the HIV/HCV co-infected patients had significantly more perseverations in the Wisconsin Card Sorting Test, which is an indicator of more severe disorders in cognitive flexibility, one of the most important aspects of executive functions [21]. Such a type of impairment leads to weaker ability to assess new information and coordinate behavior according to changing environmental circumstances.
Finding a specific profile of cognitive dysfunction seems to be very difficult, not only in HIV/HCV co-infected subjects but even in mono HIV-infected patients. Marcotte et al. found 164 distinct impairment patterns in 322 investigated HIV + subjects, among which the most common were two profiles: impairment of attention/ working memory and verbal abilities and attention/ working memory and learning impairment [4]. Lojek and Bornstein found four stable (no significant change after a 1-year follow-up) patterns of neurocognitive deficits in HIV-infected men at the group level [22]. These patterns ranged from good cognitive outcome to overall cognitive impairment. It is worth indicating that $\mathrm{HIV} / \mathrm{HCV}$ coinfected patients' profiles can differ, depending on their health condition-not only the stage of HIV infection, but also hepatitis $\mathrm{C}$ virus development. According to research by some authors, only an active hepatitis $\mathrm{C}$ virus (e.g. untreated HCV infection) causes neurological consequences in HIV RNA virally suppressed patients, resulting in cognitive function impairment [23]. Among mono hepatitis C-infected patients, only Cordoba et al. did not identify any cognitive dysfunctions $[24,25]$. The authors suggested that other factors like labeling and impact of diagnosis worsened the patients' quality of life. The investigated subjects, however, were blood donators, diagnosed just before a planned donation, had to be in good overall health condition without any noticeable cognitive impairment, which made this sample non-representative among the $\mathrm{HCV}$-infected population. A poor somatic health condition is probably a relevant factor that influences the patients' worse neurocognitive outcome. The majority of subjects investigated in this research, had AIDS, which would be an argument for worse rather than better overall health condition. Moreover, 12 of the patients researched had a history of alcohol abuse. Because HIV and alcohol abuse have multiple common sites of action that contribute to the development of liver disease, this factor could be significant in worsening not only clinical but also cognitive outcomes [26]. Further research is needed to investigate the specificity of cognitive impairment caused by both viruses, in order to better differentiate mono and dually-infected patients' needs. Such findings could bring implications for specific cognitive function training for patients with $\mathrm{HIV} / \mathrm{HCV}$ co-infection, which is not yet performed anywhere in Poland, and could be helpful in improving the quality of life in these patients.

\section{REFERENCES}

[1] M. D. Lezak, D. B. Howieson and D. W. Loring, "Neuropsychological Assessment," Oxford University Press, New York, 2004.

[2] U. S. Clark, R. A. Cohen, M. L. Westbrook, K. N. Devlin 
and K. T. Tashima, "Facial Emotion Recognition Impairments in Individuals with HIV," Journal of the International Neuropsychological Society, Vol. 16, No. 6, 2010, pp. 1127-1137. doi:10.1017/S1355617710001037

[3] K. A. Lindl, D. R. Marks, D. L. Kolson and K. L. JordanSciutto," HIV-Associated Neurocognitive Disorder: Pathogenesis and Therapeutic Opportunities," Journal of Neuroimmune Pharmacology, Vol. 5, No. 3, 2010, pp. 294-309. doi:10.1007/s11481-010-9205-Z

[4] T. Marcotte and J. C. Scott, "Evolution of Neuropsychological Issues in HIV-1 Infection during the HAART Era," In: K. Goodkin, P. Shapshak and A. Verma, Eds., The Spectrum of Neuro-AIDS Disorders: Pathology, Diagnosis and Treatment, American Society for Microbiology, Washington DC, 2008.

[5] A. Antinori, G. Arendt, J. T. Becker, B. J. Brew, D. A. Byrd, M. Cherner, D. B. Clifford, P. Cinque, L. G. Epstein, K. Goodkin, M. Gisslen, I. Grant, R. K. Heaton, J. Joseph, K. Marder, C. M. Marra, J. C. McArthur, M, Nunn, R. W. Price, L. Pulliam, K. R. Robertson, N. Sacktor, V. Valcour and V. E. Wojna, "Updated Research Nosology for HIV-Associated Neurocognitive Disorders," Neurology, Vol. 69, No. 18, 2007, pp. 1789-1799. doi:10.1212/01.WNL.0000287431.88658.8b

[6] C. M. Marra, Y. Zhao, D. B. Clifford, S. Letendre, S. Evans, K. Henry, R. J. Ellis, B. Rodriguez, R. W. Coombs, G. Schifitto, J. C. McArthur, K. Robertson and AIDS Clinical Trials Group 736 Study Team, "Impact of Combination Antiretroviral Therapy on Cerebrospinal Fluid HIV RNA and Neurocognitive Performance," AIDS, Vol. 23, No. 11, 2009, pp. 1359-1366. doi:10.1097/QAD.0b013e32832c4152

[7] A. Winston, C. Duncombe , P. C. K. Li, J. M. Gill, S. J. Kerr, R. Puls, K. Petoumenos, S. D. Taylor-Robinson, S. Emery and D. Cooper and Altair Study Group, "Does Choice of Combination Antiretroviral Therapy (cART) Alter Changes in Cereblar Function Testing after 48 Weeks in Treatment-Naive, HIV-1-Infected Individuals Commencing cART? A Randomized Controlled Study," Clinical Infectious Diseases, Vol. 50, No. 6, 2010, pp. 920-929. doi:10.1086/650743

[8] M. L. Ettenhofer, C. H. Hinkin, S. A. Castellon, R. Durvasula, J. Ullman, M. Lam, H. Myers, M. J. Wright and J. Foley, "Aging, Neurocognition and Medication Adherence in HIV Infection," American Journal of Geriatric Psychiatry, Vol. 17, No. 4, 2009, pp. 281-290. doi:10.1097/JGP.0b013e31819431bd

[9] J. J. Chen, C. B. You, W. B. Du and L. J. Li, "Prevalence of Hepatitis B and C in HIV-Infected Patients: A Meta-Analysis," Hepatobiliary Pancreat Disease, Vol. 10, No. 2, 2001, pp. 122-127. doi:10.1016/S1499-3872(11)60020-9

[10] M. Bociaga-Jasik, B. Lickiewicz, A. Kalinowska-Nowak, A. Ciesla, T. Mach and A. Garlicki, "Neurocognitive Disorders in HIV Infected Patients," HIV and AIDS Review, Vol. 9, No. 2, 2010, pp. 33-36. doi:10.1016/S1730-1270(10)60066-5

[11] D. M. Forton, H. C. Thomas and S. D. Taylor-Robinson, "Central Nervous System Involvement in Hepatitis C Vi- rus Infection," Metabolic Brain Disease, Vol. 19, No. 3-4, 2004, pp. 383-391.

doi:10.1023/B:MEBR.0000043983.42843.ac

[12] D. L. Thomas, D. Leoutsakas, T. Zabransky and M. S. Kumar, "Hepatitis C in HIV-Infected Individuals: Cure and Control, Right Now," Journal of the International AIDS Society, Vol. 14, No. 22, 2011, pp. 1-8. http://www.jiasociety.org/content/14/1/22

[13] R. Gonzalez, J. Jacobus and E. M. Martin, "Investigating Neurocognitive Features of Hepatitis C Virus in Drug Users: Potential Challenges and Lessons Learned from the HIV Literature," Clinical Infectious Disease, Vol. 41, Suppl. 1, 2005, pp. 45-49. doi:10.1086/429495

[14] D. M. Forton, H. C. Thomas, C. A. Murphy, J. M. Allsop, G. R. Foster, J. Main, K.A. Wesnes and S. D. TaylorRobinson, "Hepatitis C and Cognitive Impairment in a Cohort of Patients with Mild Liver Disease," Hepatology, Vol. 35, No. 2, 2002, pp. 433-439. doi:10.1053/jhep.2002.30688

[15] L. Kramer, E. Bauer, G. Funk, H. Hofer, W. Jessner, P. Steindl-Munda, F. Wrba, C. Madl, A. Gangl and P. Ferenci, "Scubclinical Impairment of Brain Function in Chronic Hepatitis C Infection," Journal of Hepatology, Vol. 37, No. 3, 2002, pp. 349-354. doi:10.1016/S0168-8278(02)00172-1

[16] R. C. Hilsabeck, W. Perry and T. I. Hassanein, "Neuropsychological Impairment in Patients with Chronic Hepatitis C," Hepatology, Vol. 35, No. 2, 2002, pp. 440-446. doi:10.1053/jhep.2002.31257

[17] O. Vigil, C. Posada, S. P. Woods, J. H. Atkinson, R. K. Heaton, W. Perry, T. Hassanhein, I. Grant, S. L. Letendre and the HIV Neurobehavioral Research Center (HNRC) Group, "Impairments in Fine-Motor Coordination and Speed of Information Processing Predict Declines in Everyday Functioning in Hepatitis C Infection," Journal of Clinical Experimental Neuropsychology, Vol. 30, No. 7, 2008, pp. 805-815. doi:10.1080/13803390701802354

[18] R. Fama, M. J. Rosenbloom, S. A. Sassoon, M. A. Thompson, A. Pfefferbaum, E. V. Sullivan, "Remote Semantic Memory for Public Figures in HIV Infection, Alcoholism and Their Comorbidity," Alcoholism: Clinical and Experimental Research, Vol. 35, No. 2, 2011, pp. 265-276. doi:10.1111/j.1530-0277.2010.01342.x

[19] S. P. Woods and I. Grant , "Neuropsychology of HIV," In: H. Gendelman, I. Grant, I. Everall, S. Lipton and S. Swindelss, Eds., The Neurology of AIDS, 2nd Edition, Oxford University Press, London, 2005, pp. 357-373.

[20] C. H. Hinkin, S. A. Castellon, A. Levine, T. R. Barclay and E. J. Singer, "Neurocognition in Individuals Co-Infected with HIV and Hepatitis C," Journal of Addictive Disorders, Vol. 27, No. 2, 2008, pp. 11-17. doi: $10.1300 / J 069 \mathrm{v} 27 \mathrm{n} 02 \quad 02$

[21] E. L. Ryan, S. Morgello, K. Isaacs, P. Naseer, R. N. Gerits and the Manhattan HIV Brain Bank, "Neuropsychiatric Impact of Hepatitis C on Advanced HIV," Neurology, Vol. 62, No. 6, 2004, pp. 957-962.

[22] E. Lojek and R. A. Bornstein, "The Stability of Neurocognitive Patterns in HIV Infected Men: Classification Considerations," Journal of Clinical and Experimental 
Neuropsychology, Vol. 27, No. 6, 2005, pp. 665-682. doi:10.1081/13803390490918426

[23] D. B. Clifford, M. Smurzynski, L. S. Park, T. Yeh, L. Blair, M. Arens and S. R. Evans, "Effects of Active HCV Replication on Neurologic Status in HIV RNA Virally Suppressed Patients," Neurology, Vol. 73, No. 4, 2009, pp. 309-314. doi:10.1212/WNL.0b013e3181af7a10

[24] J. Cordoba, M. Flavia, C. Jacas, S. Sauleda, J. Esteban, V. Vargas, R. Esteban and J. Guardia, "Quality of Life and Cognitive Function in Hepatitis C at Different Stages of Liver Disease," Journal of Hepatology, Vol. 39, No. 2,
2003, pp. 231-238. doi:10.1016/S0168-8278(03)00189-2

[25] J. Cordoba, J. Reyes, J. I. Esteban and J. M. Hernandez, "Labeling May Be an Important Cause of Reduced Quality of Life and Cognitive Function in Chronic Hepatitis C," American Journal of Gastroenterology, Vol. 98, No. 1, 2003, pp. 226-227.

[26] G. Szabo and S. Zakhari, "Mechanisms of Alcohol-MediAted Hepatotoxicity in Human Immunodeficiency VirusInfected Patients," World Journal of Gastoenterology, Vol. 17, No. 20, 2011, pp. 2500-2506.

doi:10.3748/wjg.v17.i20.2500 